\title{
Application of BIM with IPD in Design for Construction Project
}

\author{
Shiping Wang, Wenming Liu, Guoping Peng, Nuowei Zhang* \\ Shandong Ruison Institute of High-Performing Building Co., Ltd. Jinan City, Shandong Province, China
}

*Corresponding author: Nuowei Zhang, zhangnuowei@sina.com

\begin{abstract}
Integrated Project Delivery (IPD) is a new delivery system that fosters integration of combining design and construction in a collaborative team environment. Building Information Modeling (BIM) is a smart technological tool that make significant advancements in coordinating the planning and construction processes. IPD process with BIM technology allows all building data to maintain in a communicating platform that make all participants share data. In reality, some technical and process obstacles exist, that are hampering full implementation of IPD with BIM in the project. The paper introduced the application of IPD with BIM on the design in a project. The results showed the impact of BIM implementation on IPD mode which can result in improved productivity, better coordination, reduced energy consumption, clash and rework of construction.
\end{abstract}

Keywords: Collaboration platform; IPD projects; BIM; Design coordination

Publication date: November 2021; Online publication: November 30, 2021

\section{Introduction}

Integrated project delivery (IPD) is a distinct delivery typology, which has been considered as a strategy that drives continuous improvement for procuring a built asset. The core IPD concept is related to key stakeholders from initial phase of the project, formed a diverse, cross-functional, and multidisciplinary team $[1,2,3]$. The building information modeling (BIM) in areas of the construction industry improves design quality, and efficiently manage project, which involves all data for supporting the different applications in every phase of the project ${ }^{[4]}$. However, BIM implementation is still a challenge for the construction industry, and BIM has limited power without contractors integrating in the design phase of project ${ }^{[5]}$. Some experiences indicated some reasons for suspecting that BIM and IPD, had a lot in common ${ }^{[6]}$. The paper introduced the experiences of the contemporaneous use of BIM and IPD and showed the main effects when utilized simultaneously. We obtained the same conclusion as other studies that IPD process with BIM technology can provide a most effective approach to make right decisions in the design as well as whole phase of the project ${ }^{[7]}$.

\section{Significance of IPD and BIM}

There are more definitions about IPD in many literatures. However, the most commonly adopted definition is proposed by American Institute of Architects, which is "IPD as a project delivery approach that integrates people, organizations, business structures and exercises into a process that collaboratively harnesses the talents and insights of all project participants to optimize the results, increase value to the owner, reduce waste, and maximize efficiency through all phases of design, manufacturing and building" [8].

The BIM defined by US National Building Information Model Project committee is described as "Building Information Modeling (BIM) is a digital representation of physical and functional characteristics 
of a facility on open standards for interoperability. BIM serves as a shared knowledge resource for information about a facility forming a reliable basis for decisions during its life-cycle from inception onward" [9].

\section{Materials and IPD with BIM methods}

\subsection{Materials}

The authors worked on a building construction project that implemented application of IPD-BIM integration. The project was a new Technology Research and Development Center Building facility in Xi'an Economic Development Zone, Shaanxi Province, China. The project scope consisted of a 41,000 square meter, twelve-stories above ground and a 25,278 square meter, three-stories underground, including a threestories 415 space parking garage. The building included research centers, independent offices, communal spaces, a coffee bar, conference rooms and so on. The building heigh was 49.65 meters with frame shear wall structure. The building scheme also covered ten elevators, seven the Heating, Ventilation and Air Conditioning (HVAC) systems (Figure 1).

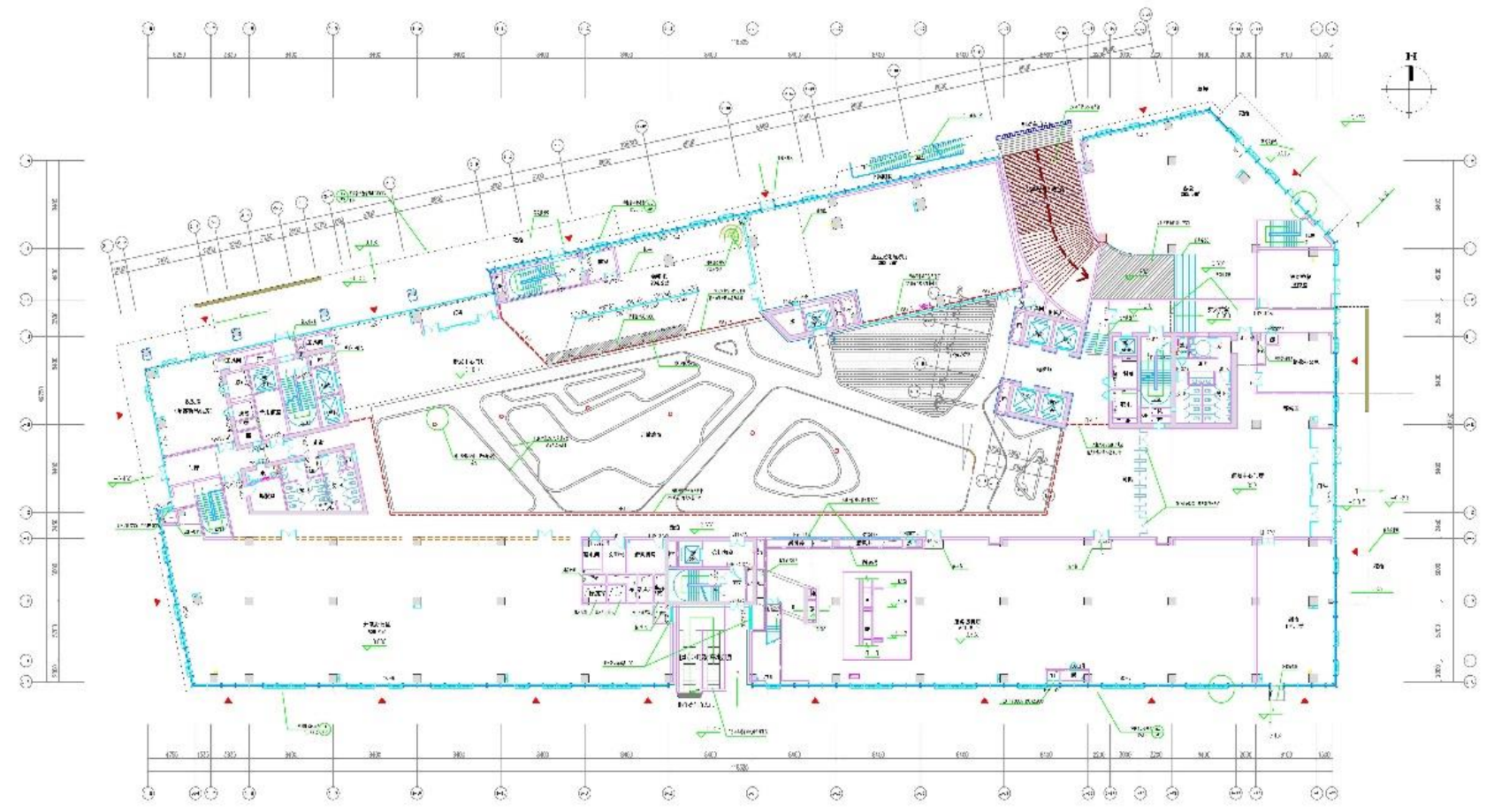

Figure 1. Architectural 2D plan of the ground level floor in the project

\subsection{Organization of project}

The architect of the project was Huahui Group, the mechanical engineer and the general contractor was Ruison Lean Construction Inc, the curtain trade partner was Jangho Group, the decoration trade partner was Zhongxiangzaide decoration design Inc, and the LEED (Leadership in Energy and Environmental Design) consultant was Ailv Energy-efficiency technology Inc. The main goal of the project was to achieve high performance building so that we built the building by assembling the most of the stakeholders to facilitate the communication each other and reduce time loss to execute the transaction. By meeting with most of main participants, the team achieved the main goal of the project before initiating the design program, that was involvement of all key project participants in the early phase of the project. The procedure was one of critical principles in the IPD process, which improved the team ability to reliably meet the project objective. 
A detailed guideline was created for enhancing the team ability to collaborate applying three dimensional (3D) tools by the project team consisting of owners, architects, engineers and general contractor. The guideline contained the ability to generate 3D models and execute design analysis with parametric objects, by Revit 2016, Navisworks.

\subsection{BIM responsibilities}

The project IPD team achieved a list of requirements to create a schematic design and submit it to the stakeholders for approval. The two dimensional (2D) architectural planning was subsequently started. Using BIM methodology, the building was redesigned and allocated the architectural model following conversion from $2 \mathrm{D}$ to $3 \mathrm{D}$ as a holistic design file. The function of data collection and analysis to create 3D model showed the powerful features of BIM. First, architectural model was created and saved. Then, the structural model was created. Mechanical, Electrical \& Plumbing (MEP) elements were created. The differences between 3D modeling and 2D drafting were analyzed. Furthermore, the refinement of objects including the dissociation of the elements was studied. The project team developed a design simulation optimization process to clarify the responsibilities and exchange information for the redesign process.

\subsection{Methods}

\subsubsection{D Design coordination process}

It was a complicated process that $3 \mathrm{D}$ design was created by import the $2 \mathrm{D}$ plans. The process required a coordination work of IPD team to bring the benefits of 3D models into full play. The project team had mastered the way to integrate the models and generated the corresponding decomposition structure consisting with all parties. In the process of generating 2D plans from 3D model, we used Revit Annotate Family to label model components in design phase of project. The purpose of the procedure was to get updating synchronously both 2D plans and to 3D model. For example, as the dimension or elevation of a pipe segment changed in 3D model, so did in 2D plans. The model components labeled by Revit Annotate Family included geometric dimension, installation elevation, equipment information.

\subsubsection{Architectural and structural model}

We created a 3D architectural model with integrating all other components using Revit 2016 in the project. The process was started by importing the 2D plans from Computer Aided Design (CAD) to Revit 2016. The 2D plans included specific items, the walls, the location of pillars, size, and layout of doors and windows. The 3D design was set up as an original model allowing all other project teams designers to integrate other components design details of the building. The project team shared the 3D design information in the whole process from design to construction. Subsequently, the structural design begun with structural analysis software. According to the calculation rules of the live and dead loads from Chinese National Code ${ }^{[10]}$. It was calculated and analyzed that included the size of foundation, column, beam and shear wall and the thickness of slab based on the required building use and the required reinforcements. With the preliminary design modifying, deepening and adjustment, structural 3D model was set up and consistent with the holistic design file to pull together structural design and architectural design into one model (Figure 2.).

\subsubsection{Mechanical analysis}

The BIM model established in design phase covered building rationality and energy consumption analyses, such as wind environment, thermal insulation of envelope performance, building sunlight, solar radiation and so on. The architectural and structural merged 3D model can be conducive to MEP engineers having an insight into the project's massing and scale. The case study was only focus on HVAC domains, therefore 
the analysis in the paper did not involve other mechanical works. With exterior and interior views from the BIM, the MEP engineers simplified the building model into an energy model, which includes the sizes of rooms as well as doors and windows. The HVAC engineers of the project using the energy model explored worksite and equipment systems for facilitating HVAC loads analysis. Design options were analyzed and validated. Subsequently, those decisions, heating and cooling loads were chosen. According to the determined design, the MEP engineers created 3D HVAC models and integrated them into the overall building model, which were responsible for maintaining the portion of the holistic design file. In order to clarify the different component work of HVAC systems in the project, Ventilation System presented as green color, Exhaust system as brown, and the size, location, type of HVAC was also presented in the merged 3D model (Figure 3.).

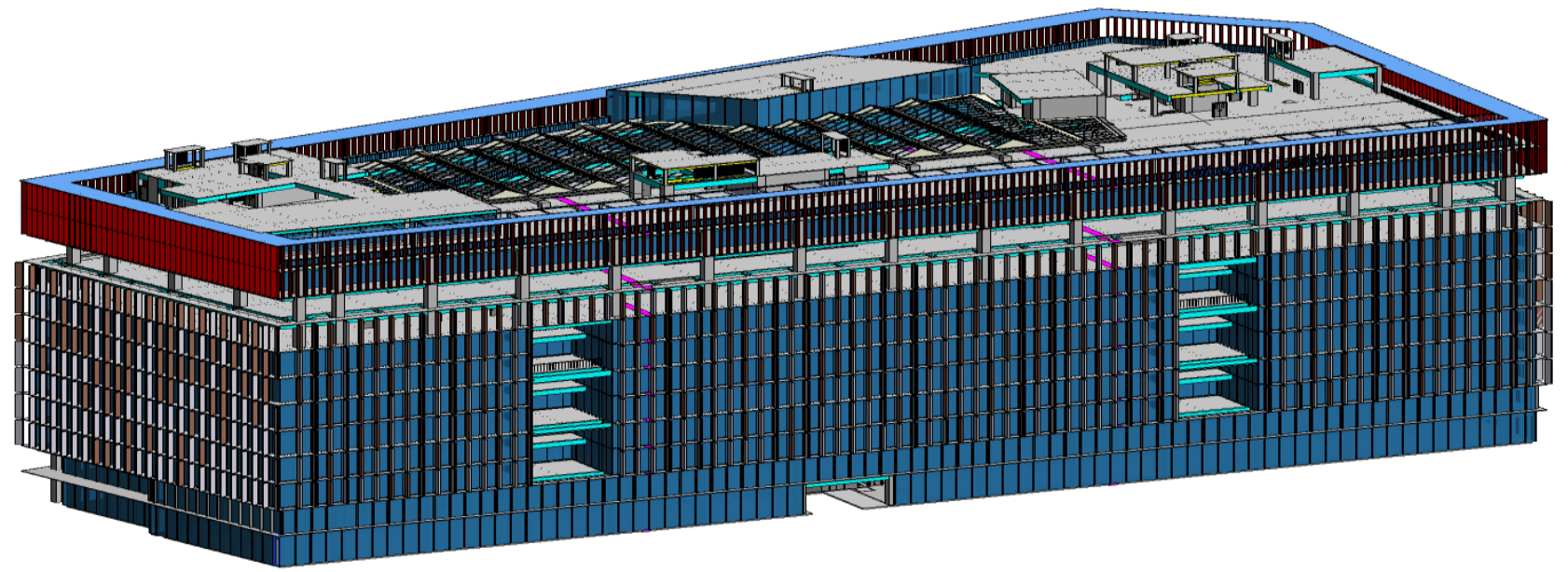

Figure 2. The merged 3D model of architecture and structure

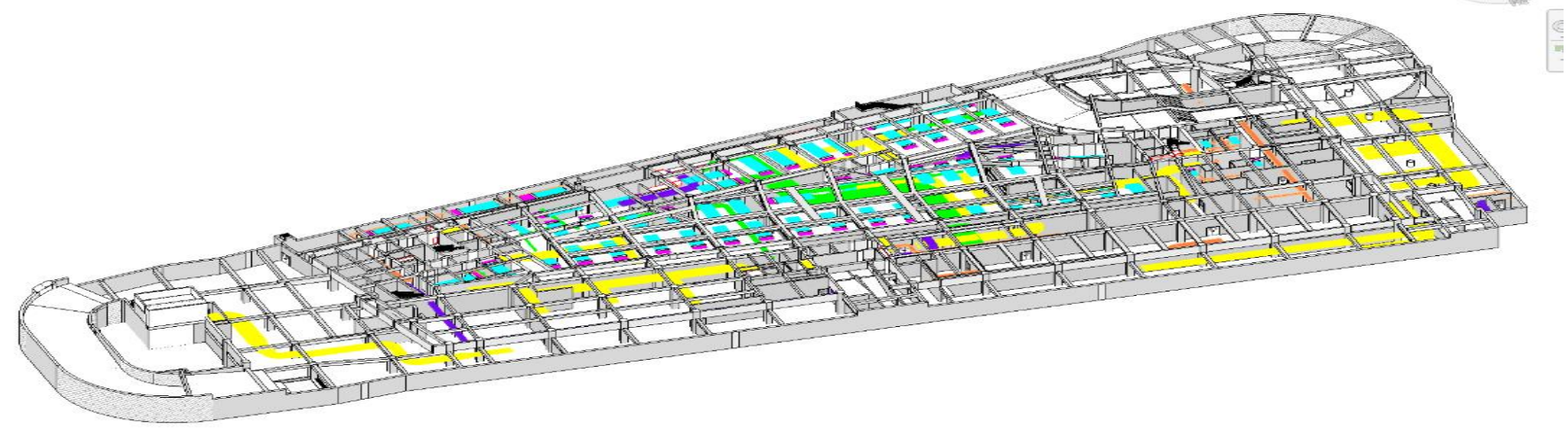

Figure 3. HVAC model

\subsubsection{Electrical distribution design}

The electrical design was developed a local file and broken down into three work sets, including strong electricity, weak electricity, and fire alarm system. The work sets were generated for each set and coordinated by each set. All the electrical drawings were presented through 2D AutoCAD to 3D model and the specific items presented in the bill of quantities. The process made 3D model present the interior lighting fixtures of different location in detail. All these lamps, steel conduits and power sockets 10A, 16A, 25A, were linked to switchgears for power. Figure 4., showed the layout of the ceiling light fixtures, wall lighting, and the related wiring system. 
The fire alarm system was also presented through 2D AutoCAD to 3D model and the specific items presented in the bill of quantity. The presented fire detectors included temperature detectors, smoke detectors, manual alarm buttons for each story and its connection with the fire alarm control panel. In order to visualize electrical and telephone cables, it was presented with drawing conduits and making notations to indicate a specific cable in 3D model. These cables included the building cables between the main power distribution boxes and the sub distribution boxes on each story, the interconnecting cables between the main boards, the interconnecting cables between the main power distribution boxes and the main power supply of the project. It was illustrated that the fixed specification properties of each cable (Figure 5.).

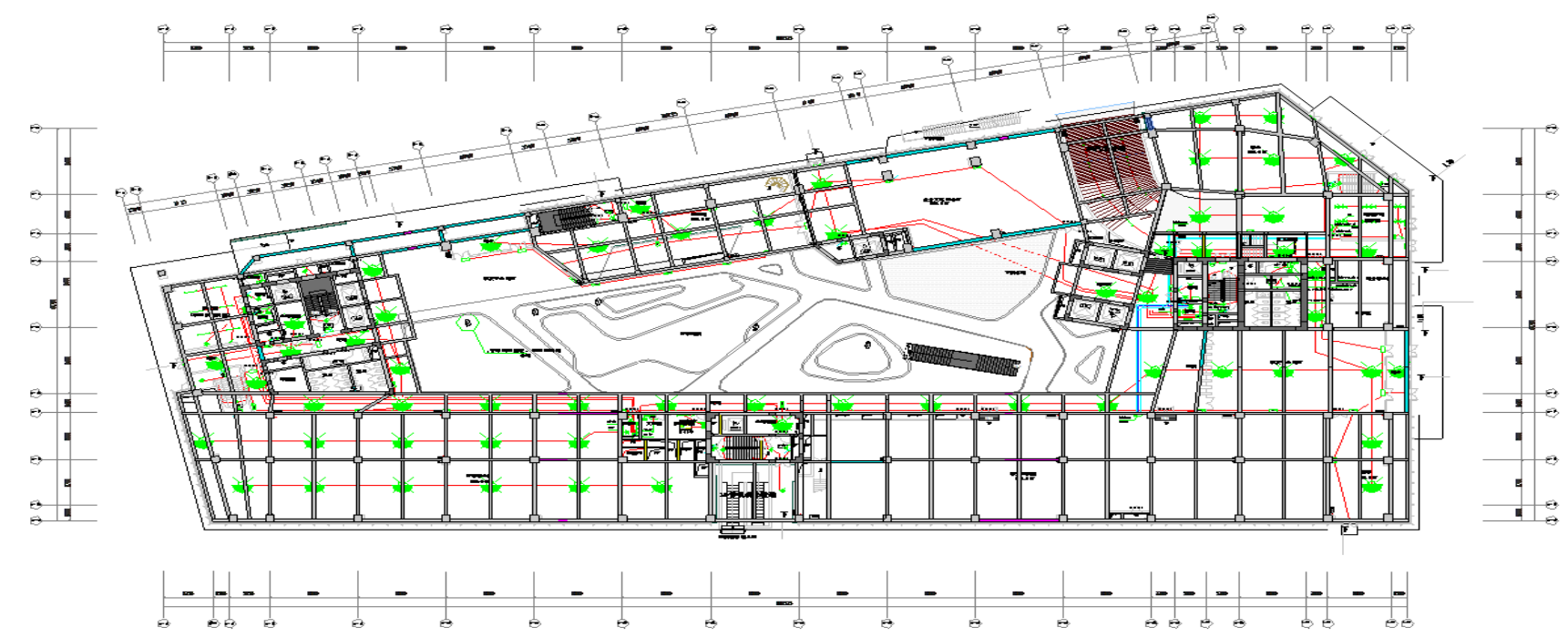

Figure 4. The layout of the ceiling light fixtures, wall lighting, and the related wiring system

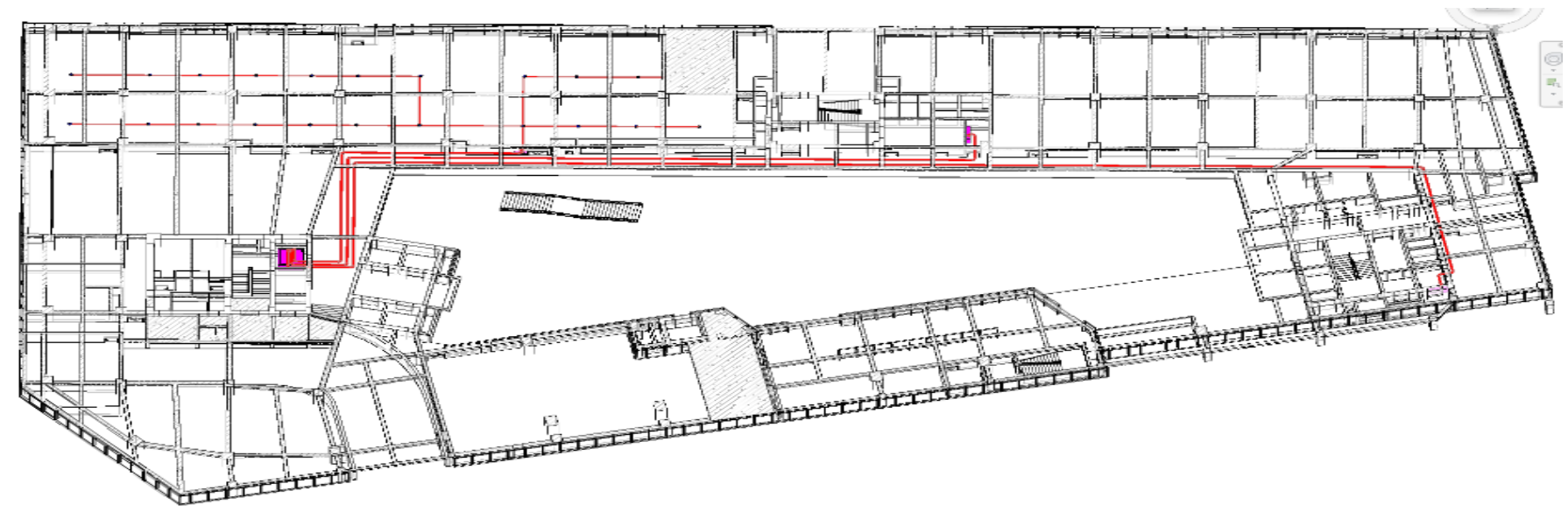

Figure 5. The fixed specification properties of each cable

\subsubsection{Plumbing design}

A local file relating plumbing design was developed, and the plumbing components presented on the specific items of the bill of quantities. The plumbing design was completed based on the needs of the requesting party and the specific items of the bill of quantity. The wells of the sewage drainages, water supply pipes, rainwater drainage pipes were given clear indication in each story of the project, as well as the plumbing fixtures, which included washrooms of both sides, diet-kitchen of underground, solar water heaters, water tanks on the roof of the building and pipefittings. The completed 2D plumbing plans were imported into Revit 2016 to create 3D model for showing all the designs about architectural, structural, 
plumbing in one model. Figure 6. showed the 3D model of design in the plumbing systems.

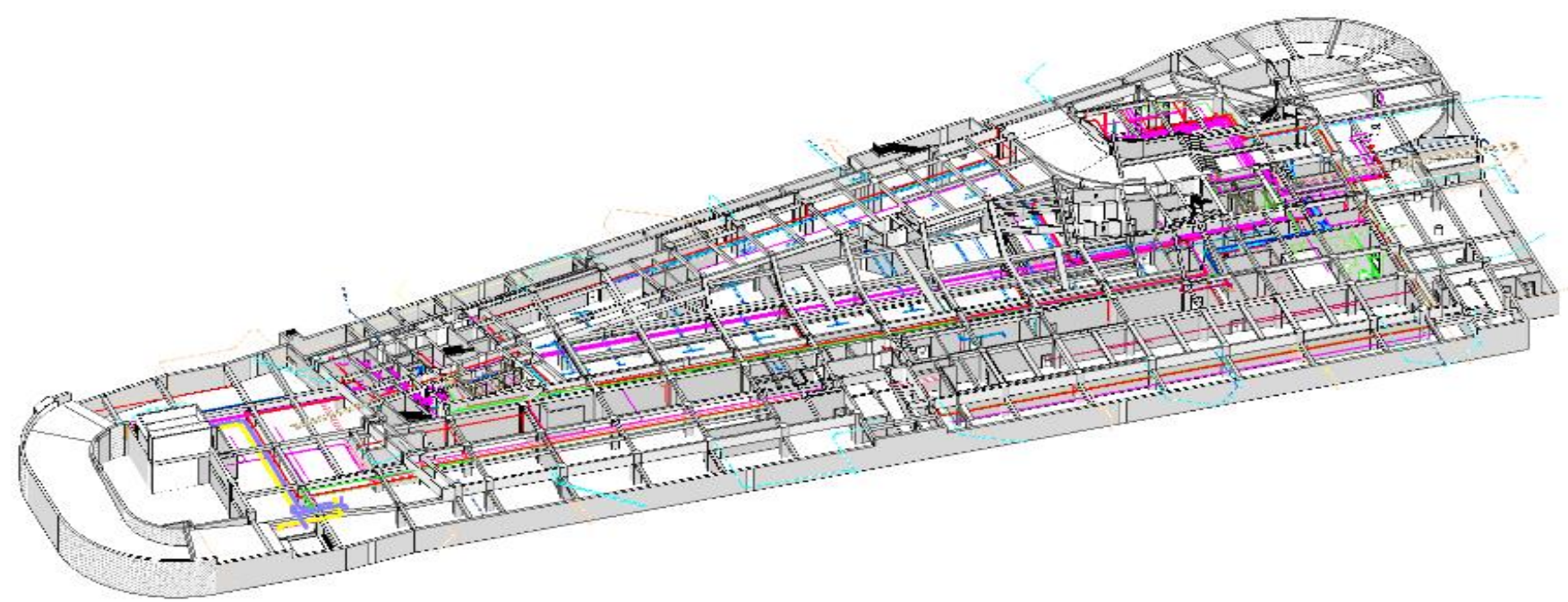

Figure 6. Plumbing model

\section{Testing results}

IPD with BIM process is primarily aimed at developing the comprehensive digital models assembles all information that connect with the construction and other phases of the project. We were mostly interested in minimizing the energy consumption and clashes in the design, that covered carrying out energy consumption analysis, clash detection and resolution with the 3D models. Virtual Environment analysis program was used for layout of HVAC, doors and windows. In the project, the indoor sunshine area (Figure 7.) of the building was increased by $12 \%$, through moving 34 wall positions and adjusting 69 window sizes in the project. The numbers of air conditioning vent were canceled by 33 with mixed mode of natural and mechanical ventilation. Revit Clash Detective module was used for defining clash tests and discovered clashes, including soft clash detection for operating space of MEP to facilitate operating such devices. In the project, there were 26 clashes between HVAC ductwork and structural framing, 93 clashes between structural framing and walls, 179 clashes between the pipes and walls, respectively. It was worth noting that most of the structural framing and walls clashes were approved, as these structural framing and walls overlap simply without resulting in delay or rework, so only 24 clashes left were needed to be resolved because there were malposition and size mismatch each other. While most of the pipes and walls clashes were also approved, as these pipes ran through the walls, that was routine project works, so only 19 clashes were needed to be resolved due to those pipes conflicting with the shear wall (Figure 8.).

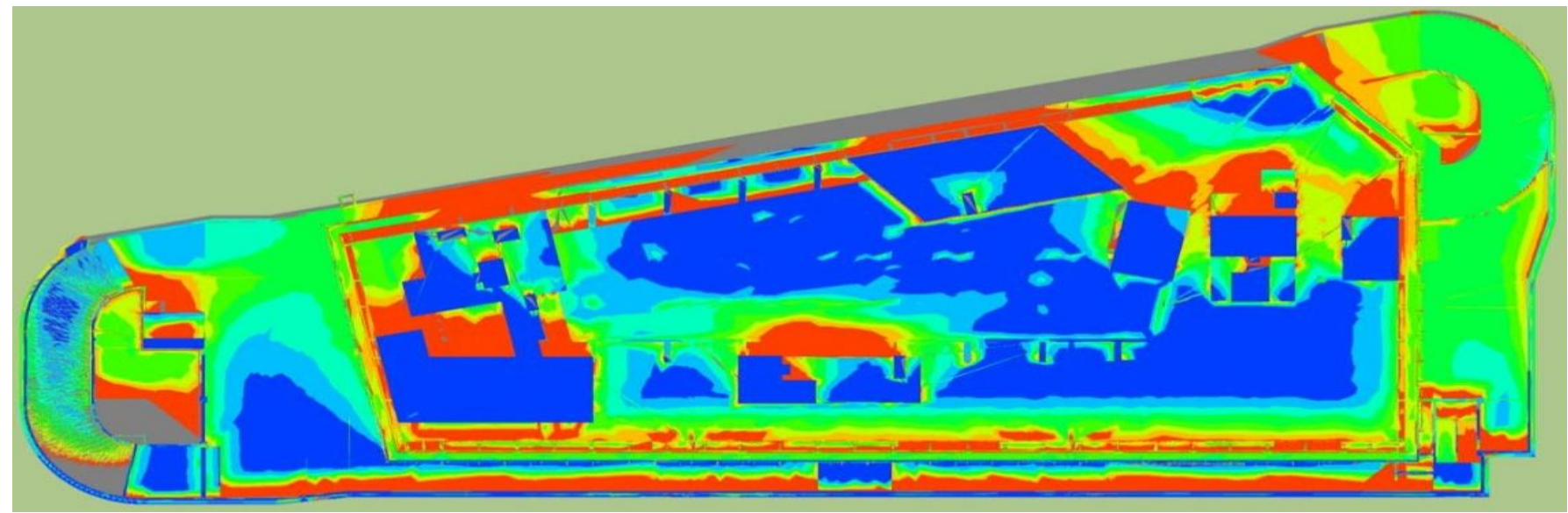

Figure 7. The indoor sunshine area analysis 


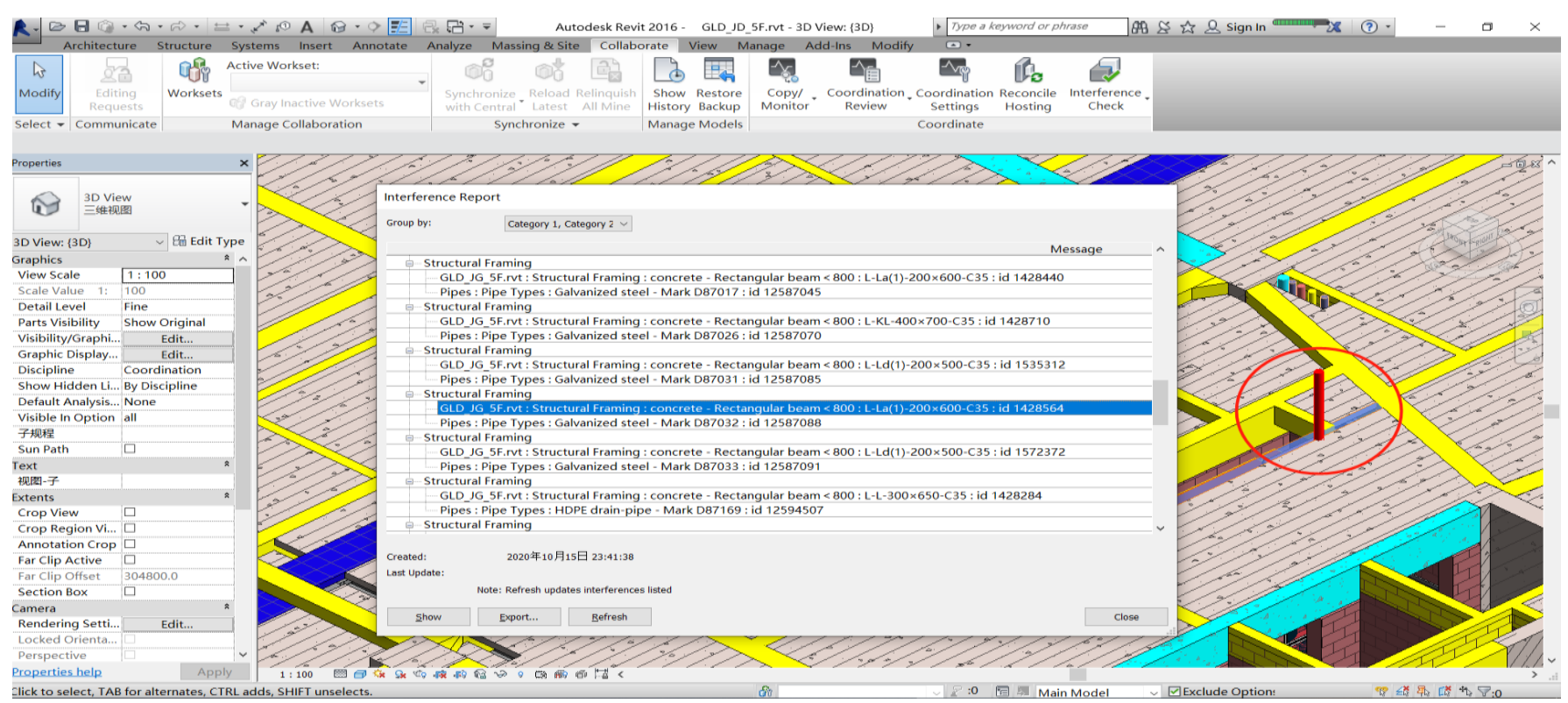

Figure 8. The view of clash detection between pipes with the shear wall

\section{Lessons learned}

The merged 3D model improved the construction and the design units adjusting the layout of the building, provided a comfortable natural ventilation, indoor lighting effect and reduction of energy consumption. In the design phase, BIM-based collaboration platform can facilitate the work of multi-functional teams in the same project model, and promote the true collaboration of all participants. This platform in the project accelerated cross-functional teams at a working level; transparency and information flow; swift identification of problems, response, and adaptation to them; and decision making as together as possible. Under these circumstances, BIM technology activated the processes of the IPD project, and realized the most potential merits and requirements of IPD projects. The key benefits of IPD with BIM methods in design phase included avoiding many conflicts because different professional software systems were exchanging in BIM-based collaboration platform to achieve collaborative design. The process can provide the more efficient and productive works for all necessary downstream applications (such as energy modeling). The multidisciplinary merged 3D model is a valuable tool in the design and construction process, which can be used in an interoperable way for reducing rework and change orders. As an example, the findings from the experience that the HVAC duct should be completed at least $75 \%$ before the other specialties could carry out effectively their work, because the duct was the most constraining ${ }^{[1]}$.

\section{Discussion and conclusion}

This paper describes cross-functional teamwork in an IPD project using a BIM-based collaboration platform. The process enhances communication exchange and mutual trust between the parties by involving all of the major parties in the design phase. The article explains how different professional project teams can use these technologies to produce specific professional models based on holistic design files for putting together a holistic 3D model. BIM is a powerful technology that necessitates the use of a collaborative platform in order to maximize profitability. BIM application can obtain benefits that are aligned with the benefits of the IPD mode, allowing it to enforce many of the IPD's requirements and advantages while combining applications. When BIM is combined with the IPD approach, it is possible to create true crossfunctional teams and improve project implementation. The methodology promotes optimal design by eliminating waste, shortening timeframes, lowering energy usage, detecting conflicts, enhancing preconstruction estimating, and speeding up the work process through information sharing. 
Much more can be done to improve the combined use of BIM and IPD. Sharing information among professionals from various teams is no longer sufficient. In the future, combining BIM and IPD can aid in getting more precise designs, collaborating more closely with professional teams during the design process, and improving coordination issues and optimization schemes early in the design development process.

\section{Acknowledgments}

The authors gratefully acknowledge the support by the Housing and Urban-Rural Development Department of Shandong Province "specific topic" (No. 2020-K1-7).

\section{Disclosure statement}

The author declares no conflict of interest.

\section{References}

[1] Matthews O, Howell GA, 2005, "Integrated Project Delivery: An Example of Relational Contracting," Lean Construction Journal (LCJ), 2: 46-61.

[2] Kent DC, Becerik-Gerber B, 2010, "Understanding Construction Industry Experience and Attitudes toward Integrated Project Delivery," Journal of Construction Engineering \& Management, 136: 815825.

[3] Rahim SA, Mohd Nawi MN, Nifa FAA, 2016, "Integrated Project Delivery (IPD): A Collaborative Approach to Improve the Construction Industry," Advanced Science Letters, 22: 1331-1335.

[4] Porwal A, Hewage KN, 2013, "Building Information Modeling (BIM) Partnering Framework for Public Construction Projects," Automation in Construction, 31: 204-214.

[5] Atul P, Kasun N, 2013, "Building Information Modeling (BIM) Partnering Framework for Public Construction Projects," Journal of Automation in Construction, 31: 204-214.

[6] Halttula H, Aapaoja A, Haapasalo H, 2015, "The Contemporaneous Use of Building Information Modeling and Relational Project Delivery Arrangements," Procedia Economics and Finance, 21: 532539.

[7] Solnosky R, Parfitt M, Holland R, 2014, "IPD and BIM-Focused Capstone Course based on AEC Industry needs and Involvement," Journal of Professional Issues in Engineering Education \& Practice, 140: A4013001.

[8] 2007, American Institute of Architects (2007a). "Integrated Project Delivery: A Guide," http://www.msaipd.com/IPD Guide 2007.pdf. Accessed 17 July 2010.

[9] National Institute of Building Sciences (NBIMS), 2007, "National Building Information Modeling Standard", Version.1-Glossary, 149.

[10] Ministry of Housing and Urban-Rural Development of the People's Republic of China (MOHURD), 2012, "Load code for the design of building structures," GB 50009-2012, 8-9.

[11] Staub-French S, Khanzode A, 2007, “3D and 4D Modeling for Design and Construction Coordination: Issues and Lessons Learned," Electronic Journal of Information Technology in Construction, 12: 381 407. 